\title{
PSICOLOGIA ESCOLAR E EDUCAÇÃO INCLUSIVA: DA FORMAÇÃO ÀS PRÁTICAS DE PSICÓLOGAS ESCOLARES DE MATO GROSSO DO SUL
}

\author{
PSICOLOGIA ESCOLAR Y EDUCACIÓN INCLUSIVA: DE LA FORMACIÓN A \\ LAS PRACTICAS DE PSICOLOGIA ESCOLARES DE MATO GROSSO DEL SUR
}

\author{
SCHOOL PSYCHOLOGY AND INCLUSIVE EDUCATION: FROM \\ GRADUATION TO PSYCHOLOGISTS SCHOOL PRATICES FROM MATO \\ GROSSO DO SUL
}

\author{
Suéllen Soares ALTRÃO ${ }^{1}$ \\ Denise Mesquita de Melo ALMEIDA ${ }^{2}$
}

RESUMO: Este artigo resulta de um estudo que teve por objetivo conhecer concepções e práticas de psicólogas/os escolares em relação à Educação Inclusiva. Para tanto, destacou a formação e a atuação de profissionais institucionalmente ligados a redes municipais de educação de municípios da região sul de Mato Grosso do Sul: Ivinhema, Batayporã e Glória de Dourados. Por meio de pesquisa qualitativa na modalidade estudo de caso buscou-se compreender fatores que influenciaram nas escolhas pela atuação na Psicologia Escolar e Educacional, processos de qualificação profissional para 0 exercício neste campo, bem como os desafios enfrentados em suas trajetórias para a promoção da inclusão escolar nos sistemas de ensino em que atuam. Os resultados sugerem que a presença de psicólogos escolares na região ainda é inexpressiva e as profissionais atuantes, embora demonstrem conhecimentos sobre a inclusão, encontram dificuldades no planejamento e na implementação de projetos voltados à construção de práticas educativas inclusivas.

PALAVRAS-CHAVE: Educação inclusiva. Psicologia. Formação.

RESUMEN: Este articulo resulta de un estudio que tuvo por objetivo conocer concepciones y prácticas de psicólogas/as escolares en relación a la Educación Inclusiva. También, destaco la formación y actuación de profesionales institucionalmente unidos a redes municipales de educación de la regio sur de Mato Grosso del Sur: Ivinhema, Batayporã y Gloria de Dorados. Por medio de investigación cualitativa en la modalidad estudio de caso se buscó comprender factores que influenciaron en las decisiones por la actuación en la Psicología Escolar y Educacional, procesos de cualificación profesional para el ejercicio en este campo, bien como los desafíos enfrentados en sus trayectorias para la promoción de la

\footnotetext{
${ }^{1}$ Universidade Federal da Grande Dourados (UFGD), Dourados - MS - Brasil. Especialista em Educação Especial. Foi bolsista pela UFGD no Programa Institucional de Bolsas de Incentivo à Docência - PIBID. ORCID: https://orcid.org/0000-0003-2242-5870. E-mail: suellenaltrao@gmail.com

${ }^{2}$ Universidade Federal da Grande Dourados (UFGD), Dourados - MS - Brasil. Professora Adjunta no Curso de Psicologia. Doutora e Mestre em Educação pela Universidade Estadual de Campinas (UNICAMP). Docente na área da Psicologia Educacional e Educação Inclusiva. ORCID: http://orcid.org/0000-0002-0122-9697. E-mail: denisealmeida@ufgd.edu.br
} 
inclusión escolar en los sistemas de enseñanza en que actúan. Los resultados sugieren que la presencia de psicólogos escolares en la región todavía es inexpresiva y las profesionales actuantes, aunque demuestren conocimientos sobre la inclusión, encuentran dificultades en la planificación y en la implementación de proyectos dirigidos a la construcción de prácticas educativas inclusivas.

PALABRAS-CLAVES: Educación inclusiva. Psicologia. Formación.

ABSTRACT: This article results from a study that aimed to knowing conceptions and practices of school psychologists related to Inclusive Education. Thefore, it evidences the training and work of professionals institutionally linked to municipal education networks of municipalities in southern Mato Grosso do Sul: Ivinhema, Batayporã and Gloria de Dourados. By means of qualitative research in the case study modality, we tried to understand the influences to choosing onto School and Educational Psychology, professional qualification processes for acting in this field, as well as the challenges faced in their paths for the promotion of inclusion school systems they work with. The results suggest an inexpressive presence of school psychologists working in the region. Besides that, professionals acting in this area have been facing difficulties into planning and implementing inclusives educational practices construction, despite their knowledge about inclusion.

KEYWORDS: Inclusive education. Psychology. Formation.

\section{Introdução}

$\mathrm{Na}$ atualidade as políticas inclusivas consideram as pessoas como dotadas de individualidades únicas. Ao cogitar os indivíduos em suas singularidades, levam-se em conta suas percepções, visões de mundo e seus diferentes modos de se comunicar com os outros. Sob esta perspectiva, as pessoas deixam de ser vistas de modo isolado e passam a ser reconhecidas como sujeitas/os históricas/os e sociais que apresentam modos de ser socialmente produzidos. Assim, considerando a complexidade que resulta deste olhar, sobretudo para a Educação, indagamos a respeito de como se faz a atuação da Psicologia neste campo. Perguntamo-nos sobre os processos formativos proporcionados a psicólogas/os para o exercício profissional no campo educacional, em especial quando se tem no horizonte a promoção e implementação de práticas inclusivas nos sistemas de ensino públicos.

Observamos que historicamente a escola tem se apresentado como um espaço alicerçado em ideários que visam homogeneização e hierarquização de práticas institucionais pouco abertas às diferenças e às diversidades em contraponto às contemporâneas políticas de educação inclusiva. E é justamente no contexto deste 
contraponto, onde emergem conflitos e interesses antagônicos, que a formação e as práxis profissionais de psicólogas/os vêm se delineando. Daí a justificativa para se questionar como tem se constituído a atuação do profissional de Psicologia Escolar? Quais os desafios encontrados pelas/os profissionais na escola? Qual olhar apresentado pelos sujeitos que estão implicados na instituição acerca da Psicologia Escolar? Como a Psicologia Escolar pode auxiliar na promoção de práticas inclusivas? E, por fim, que estratégias precisam ser adotadas nos processos de formação inicial de psicólogas/os para que estes profissionais consigam assumir a responsabilidade pela promoção da inclusão escolar e alcançar êxito nas intervenções que realizarem com este objetivo?

Frente a este cenário, com o intuito de refletir sobre a maneira como estes questionamentos têm permeado a produção do campo da Psicologia Escolar no estado de Mato Grosso do Sul nos dirigimos às prefeituras dos sete municípios que constituem a região sul deste estado. E em busca de localizar os profissionais da Psicologia Escolar atuantes nestas localidades consultamos os setores responsáveis pelos recursos humanos destas sessões administrativas. Este procedimento nos permitiu verificar que juntas estas prefeituras admitem cerca de vinte psicólogas/os em seus quadros funcionais.

No entanto, este mapeamento denotou que dentre os vinte psicólogos institucionalmente vinculados às prefeituras da região sul de Mato Grosso do Sul, dezessete têm sua atuação desempenhada em Centros de Referência Especializados de Assistência Social (CREAS), Centros de Referência de Assistência Social (CRAS) e em unidades de atenção básica de saúde (SUS). Apenas três das prefeituras consultadas durante o período em que o estudo foi realizado (2017 e 2018) lotavam profissionais da Psicologia diretamente em seus sistemas de ensino municipais: Ivinhema, Batayporã e Glória de Dourados.

As reflexões que apresentamos aqui decorrem do estudo que foi desenvolvido a partir da interlocução com duas das psicólogas escolares localizadas por este mapeamento ${ }^{3}$. Portanto, a partir daqui apresentaremos as análises que tecemos acerca da tradição dos cursos de formação inicial de psicólogos em nosso país enfatizando os limites e as contribuições oferecidas à qualificação de psicólogos para a área escolar e educacional. Discutiremos as referências técnicas vigentes norteadoras da atuação de psicólogos na Educação Básica, ao tempo em que nos dedicaremos à reflexão sobre o lugar da educação e da inclusão escolar nos processos iniciais de formação de

${ }^{3}$ Por questões operacionais a pesquisa não alcançou a representante do município de Glória de DouradosMS. 
psicólogos. Estas ponderações constituem as lentes com as quais observamos e significamos as experiências compartilhadas sobre a passagem do processo formativo inicial às práxis objetivas das psicólogas participantes da pesquisa relacionadas à produção e implementação de práticas inclusivas nos sistemas de ensino que integram.

\section{A formação de psicólogas/os escolares no Brasil: da patologização do indivíduo às práticas educativas inclusivas}

Conforme temos enfatizado desde trabalhos anteriores ${ }^{4}$, a Psicologia se estrutura efetivamente como ciência e profissão em nosso país a partir de sua relação com os institutos e laboratórios de pesquisa em Educação. Embora se trate de uma profissão recentemente reconhecida, cuja regulamentação e o currículo mínimo para seus cursos de graduação foram conquistados em lei apenas no início da década de 1960, o conhecimento psicológico já influenciava pesquisas em Educação desde muito antes. De acordo com Antunes (2008), Patto (2004) e Oliveira-Menegotto (2015) historicamente, a Psicologia Educacional foi inserida no contexto brasileiro da primeira república quando as ciências e a política eram significativamente marcadas por um viés higienista, comprometido com o anseio por inscrever a nação num cenário de desenvolvimento inspirado no modelo europeu e norte-americano de meados do século XIX e início do século XX.

O ideário político e cultural daquele momento acreditava que a separação entre indivíduos mais e menos aptos aos processos de aprendizagem poderia favorecer $\mathrm{o}$ desenvolvimento e a implementação de modelos pedagógicos mais capazes de atender aos interesses da economia que iniciava a se organizar sob a égide capitalismo emergente. Assim, conforme salienta Oliveira-Menegotto (2015), os primeiros contatos que tivemos entre psicologia e a escola priorizavam o desenvolvimento de técnicas e recursos destinados ao alcance destes objetivos. A ética da padronização e da universalização era tomada como ponto de partida para a realização dos estudos e o delineamento de suas práticas. As diferenças e as singularidades eram, na maioria das vezes, lidas como desvios à normalidade e consequentemente interpretadas sob paradigmas binários que focalizavam as observações polarizando as relações em contrapontos como saúde-doença, normal-anormal, moral-imoral.

\footnotetext{
${ }^{4}$ Almeida e Geller (2018).
} 
As intervenções decorrentes tinham por objetivo otimizar os investimentos, direcionar os mais aptos a escolas destinadas à formação para o desempenho de profissões consideradas de nobre status social, enquanto os menos aptos seriam direcionados para escolas destinadas à qualificação profissional para o desempenho funções operacionais e afins. Quanto às singularidades, as intervenções eram, via de regra, direcionadas à correção dos desvios com vistas à promoção do retorno do desenvolvimento ao eixo padrão. Com isto, de acordo com Patto (2004), Viegas (2015) e Kassar (2016) algumas teorias psicológicas sobre o desenvolvimento e a aprendizagem gestadas naquele contexto contribuíram com a legitimação, ou ainda com a disseminação, de preconceitos que transformavam características ligadas à classe, ao gênero e à raça em justificativas para conversão de diferenças em desigualdades com impactos sociais, culturais e econômicos.

No entanto, desde a década de 1980 muitos estudos foram realizados. Os efeitos das concepções geradas ali, sobretudo suas implicações para a organização das escolas e das práticas pedagógicas foram amplamente investigados por importantes teóricos do país. Entre os efeitos observados, um dos mais significativos foi apontado por Patto (1984) e diz respeito à utilização de argumentos que utilizavam os determinismos biológicos e/ou sociais para justificar a fracasso escolar. Com isto, eximiam as instituições escolares da responsabilidade de refletir sobre seu funcionamento e finalidades, e, contribuíam para a permanência e a ampliação dos processos de exclusão escolar e social.

Esta crítica revolucionou o universo da psicologia escolar no Brasil e mobilizou nossa comunidade científica ao longo da década de 1990 e da primeira década dos anos 2000 para a promoção de estudos que evidenciam o desenvolvimento humano e a aprendizagem como processos relacionais complexos e constituídos multifatorialmente. Do mesmo modo, influenciou a reformulação das matrizes curriculares dos cursos de psicologia para uma formação de psicólogos capazes não só de compreender o desenvolvimento por uma ótica ampliada, mas, sobretudo, capazes de promover intervenções em diferentes dimensões, setores e práticas das escolas com vistas à promoção da equidade social por meio da inclusão e da melhoria da qualidade das relações de ensino-aprendizagem.

A escola de Educação Básica também se transformou bastante ao longo deste período: a democratização do acesso e as estratégias para a permanência de todos os alunos na escola tornaram-se o alvo das principais políticas educacionais. O que, de 
acordo com Mantoan (2003), demandou um significativo esforço de transformação das escolas e das práticas pedagógicas para o alcance eficiente destes objetivos. Neste sentido, destacamos a importância das reflexões conduzidas por Souza (2010) e Asbahr (2014), entre outros, que pautaram que a atuação de psicólogos nesta escola que emergia exigiria dos profissionais da psicologia o desenvolvimento de habilidades e competências técnicas para além da utilização de testes com finalidades classificatórias, do encaminhamento de alunos com deficiências para serviços especializados segregadores e/ou de intervenções psicopedagógicas individuais com viés clínico aos moldes médicos.

A escola pensada sob a perspectiva inclusiva passou a demandar de psicólogos novas posturas e conhecimentos. Instrumentos que vão desde a compreensão das legislações - uma vez que as políticas públicas oferecem o suporte para circunstâncias que são vivenciadas nas escolas -, até a experiência cotidiana das relações de aprendizagem e de organização do ambiente escolar. Conforme Oliveira \& Dias (2016), a escola inclusiva demanda de psicólogos a compreensão de que relações educacionais são marcadas por transições que redirecionam o nosso olhar e produzem novas significações. Devido a isso, a área de Psicologia Escolar precisa se despojar do olhar categorizador que fundamentou os primeiros passos deste campo, para se dedicar à visão que favoreça o desenvolvimento das potencialidades de todas as pessoas.

Estas avaliações repercutiram na regulamentação da profissão de psicólogos, o que resultou no ano de 2013 na promulgação pelo Conselho Federal de Psicologia de Referências Técnicas para a atuação de Psicólogos na Educação Básica. Em consequência, os cursos de graduação em Psicologia foram comprometidos com a formação de profissionais da Psicologia Escolar com um novo perfil. Profissionais habilitados para a promoção, com a participação de toda a comunidade escolar, da discussão sobre lacunas e conflitos vivenciados na escola que incidem sobre o aprender. Habilitados para o desenho de estratégias frente aos desafios cotidianos que envolvem desde a análise do projeto político pedagógico que direciona os passos da escola, passando pela reflexão dos processos de aprendizagem sem desatrelá-los das condições sociais, culturais e históricas em que são engendrados, alcançando até o desempenho de mediações para a expressão da subjetividade dos educandos.

Os cursos de graduação, portanto, atualmente são responsáveis pela formação de psicólogas/os capacitadas/os para o diálogo com a comunidade, para a atuação junto aos professores, para a promoção da formação continuada de professores e outros 
profissionais da escola e para o trabalho grupal com os estudantes, com vistas à construção de espaços de emancipação e promoção da relação família-escola. Neste estudo nos propusemos a conhecer as trajetórias profissionais de psicólogas que atuam na área escolar, vinculadas institucionalmente às secretarias de educação de municípios da região sul de Mato Grosso do Sul, objetivando justamente conhecer como seu deu a passagem do universo das construções teóricas - bastante presentes nos processos de formação inicial - às práxis, propriamente ditas, no mundo do trabalho.

\section{Psicólogas Escolares da região Sul de Mato Grosso do Sul: do ensino superior ao mundo do trabalho}

Como dissemos, nesta pesquisa enfocamos Psicólogas Escolares de municípios da região sul de Mato Grosso do Sul: Ivinhema, Glória de Dourados e Batayporã. Buscamos compreender a visão destas/es profissionais em relação à Educação Inclusiva. Para tanto, nos propusemos a conhecer suas concepções e práticas na relação com a Instituição escolar e a Educação Especial sob a perspectiva da Educação Inclusiva, bem como conhecer como estas avaliam o efeito de suas intervenções sobre o processo de construção deste novo modelo educativo. Para isso, este estudo foi elaborado sob a perspectiva da abordagem qualitativa, por meio da metodologia de estudo de caso, que envolve desde observações, entrevistas semiestruturadas, análise de documentos, entre outros. É uma pesquisa qualitativa, pois utilizamos de um modelo que deseja explicar as situações analisadas.

A metodologia de estudo de caso, conforme sugerido por Rosa (2013) é uma generalização analítica, pois propõe um modelo que é suscetível à análise e também pode ser estendido para outros casos. Segundo André (1984), o estudo de caso também favorece na divulgação de pontos de vista distintos e tem como objetivo apresentar a realidade pesquisada de modo integral (ANDRÉ, 1984, apud ROSA, 2013 p. 72). Para isso, definimos que inicialmente o caso, especificamente neste trabalho, é restrito à análise da atuação de Psicólogas Escolares e destaca-se por ser exploratório, já que inicialmente realizamos um mapeamento das profissionais que atuam nas regiões específicas de Mato Grosso do Sul e, posteriormente, buscamos conhecer a realidade das profissionais atuantes. Cabe observar, que nos inspiramos na pesquisa de FloresMendoza (1997) para a elaboração do roteiro de entrevistas, pois esta realizou um 
estudo exploratório em Mato Grosso do Sul, a fim de compreender como tais profissionais atuam em relação às populações com deficiência.

Conforme sugere Rosa (2013), após a análise do material coletado, buscamos realizar, neste trabalho, uma análise de enunciação. Tal categoria de análise se destaca por não colocar o discurso como algo findado, ao contrário, tal processo é percebido como dinâmico e fluído. Deste modo, procuramos analisar também as contradições e incongruências apresentadas nos discursos; realizamos a organização do material coletado; relacionamos os discursos que são comuns e aqueles que surgem de modo separado; analisamos a regularidade com que algumas temáticas apareciam no discurso; procuramos as rupturas com que o discurso era delineado, considerando, por exemplo, as alternâncias e a necessidade de voltar em determinados assuntos.

Almeida (2014) sugere que é de suma importância que a/o pesquisadora/o fundamente seu estudo através de um olhar crítico, para que este esteja atento a possíveis incongruências que possam perpassar o estudo. Conforme a autora sugere, este processo se constrói a partir de "um desafio ao movimento do pensamento que permite construir a superação da realidade imediata, num movimento reflexivo, não mecânico, que permite a expressão do conhecimento, sempre provisório, apreendido da realidade" (ALMEIDA, 2014, p. 68).

Através da entrevista realizada com as Psicólogas escolares, observamos que ambas perceberam a necessidade de maiores informações, trabalhos e indicações de leituras durante a formação inicial. Para sanar tais dúvidas, as mesmas procuraram especializações e diálogos com profissionais que já atuaram e/ou atuam na área.

A minha formação em Psicologia na época, era psicologia escolar, a questão até mesmo da educação especial era muito pobre, era recente. [...] A gente não tinha na época estágio dentro da APAE, mas recebia os alunos. Daí quando a gente se interessava por esse atendimento, os professores na verdade desmotivavam a gente, "ah, você não vai ter tanta experiência, por que esses alunos são muito frageizinhos, eles são faltosos [...] daí você vai ficar perdendo aula de estágio.” Então assim, a gente saiu totalmente cru, né? Sem saber nada (informação verbal $)^{5}$.

Conforme salientaram as profissionais entrevistadas, no decorrer da formação inicial o curso ofereceu pouco suporte para a atuação na área educacional. Devido a isso, é de relevância pontuarmos a necessidade de os cursos de formação inicial incluírem disciplinas que abarquem a relação da psicologia e a educação e que também

${ }^{5}$ Entrevistada A (entrevista concedida em 10 de outubro de 2018). 
instiguem a/o estudante a conhecer a realidade escolar. Como exposto anteriormente, a atuação a partir da perspectiva inclusiva demanda um novo posicionamento desta/e profissional e, sabe-se que a prática também é fundamentada pelo arcabouço teórico que a/o psicóloga/o dispõe para manejar as situações vivenciadas na escola.

As Psicólogas entrevistadas destacaram que não optaram pela atuação na área de Psicologia Escolar após a formação. A entrevistada B enfatizou “Aí eu pensei: poxa, eu não gosto dessa área, não é isso que eu quero pra mim. Na hora eu tinha acabado de me formar, trabalhei no frigorífico por dois anos". Através da pontuação que as mesmas fizeram durante a entrevista, a não escolha pela área advém ora da ausência de materiais e conteúdos que divulgassem o fazer da psicologia no campo educacional, ora da ausência de incentivo para atuar neste âmbito.

Além disso, dentre os desafios da prática mais enfatizados por ambas as profissionais, refere-se à solicitação da escola para que a Psicóloga Escolar atue de acordo com a perspectiva clínica.

Eles [os professores] falam assim: "Eu não consigo ficar com esse menino na sala, o menino é mal-educado, sei lá o que: vai pra psicóloga. A psicóloga tem que resolver". Um dia eu falei: "Moço, eu sou a psicóloga, [...] não consigo fazer magia, meu sonho, juro por Deus, se eu tivesse uma varinha eu falava assim 'tim', o moleque tá ótimo, mas eu não tenho, eu não sou, eu não tô fazendo este tipo de trabalho aqui ainda [...]".Eu deixo claro: eu vou levar, mas é um trabalho que demora muito na clínica, que a família acompanha, que o pai acompanha, que a mãe acompanha, vão lá, eles pagam um valor significativo pra aquilo, levam toda sessão, às vezes eu demoro três anos e isso [por]que sou comportamental (informação verbal) ${ }^{6}$.

Observamos, então, que há certo conflito em relação a área de atuação desta profissional, que muitas vezes é solicitada pela instituição com a finalidade de resolver todos os problemas que assolam a comunidade escolar. Porém, tais dificuldades perpassam os muros escolares, principalmente quando consideramos que a escola também é uma extensão da sociedade. É evidente também neste relato um esforço da profissional em salientar que a atuação da psicóloga na escola é distinta da área clínica. Porém, como temos a disseminação maior do campo clínico, construído também historicamente pelos trabalhos realizados no campo da Psicologia já destacados no corpo deste trabalho por Antunes (2008), observamos uma cobrança para que a profissional atue desta forma.

${ }^{6}$ Entrevistada B (entrevista concedida em 10 de outubro de 2018). 
Ademais, conforme salientado por Oliveira-Menegotto (2015) historicamente cabia à psicologia atender as demandas solicitadas pela escola, objetivando "consertar" e "disciplinar" as/os estudantes. Desta forma, "a escola demandava-lhe curar o alunoproblema e devolvê-lo sadio" (OLIVEIRA-MENEGOTTO, 2015. p. 379). As dificuldades escolares não se restringem ao comportamento da/o aluna/o, ao contrário, estendem-se para a construção histórica, cultural, política e econômica do país. Ainda em relação aos desafios vivenciados pelas profissionais, convém evidenciar que dentre as propostas apresentadas para a superação da visão de atuação clínica na escola, as psicólogas sugerem que seja realizado o acompanhamento grupal de pais, crianças e professores, de modo que os conflitos sejam compartilhados e trabalhados em conjunto; a divulgação das possibilidades de atuação no campo da psicologia escolar e a relevância da coparticipação de profissionais do Atendimento Educacional Especializado (AEE) através de diálogos, materiais e intervenções.

As Psicólogas Escolares afirmaram que procuram sempre dialogar com os profissionais sobre o regimento escolar e o projeto político pedagógico, além de outras legislações como a LDB e o ECA. As mesmas consideram esta função necessária na atuação da/o Psicóloga/o nas redes municipais, pois as divulgações de tais legislações auxiliam na garantia de direitos para as/os familiares, crianças e professores/as.

Assim, hoje eu já conquistei muito aqui, eu sou ouvida, as pessoas vem tirar dúvida comigo, as pessoas pedem - vê isso aqui do MEC-, vem consultar. [...] Nós montamos um tempo atrás, as normas as regras, o regimento do aluno incluso, o regimento escolar também (informação verbal) ${ }^{7}$.

Constatamos, através deste relato, que é crucial promover a reflexão acerca dos projetos que norteiam as práticas escolares e contribuir para a reflexão da importância destes projetos. Tais reflexões confirmam as sugestões feitas pelas autoras Asbahr (2014) e Souza (2010), quando salientam a necessidade de as/os profissionais de Psicologia Escolar acompanharem e conhecerem as políticas públicas e legislações que embasam às práticas escolares.

Ademais, a/o Psicóloga/o Escolar também pode legitimar uma atuação voltada para a interdisciplinaridade, fomentando a cooperação de toda a equipe em ações realizadas na instituição. Faz-se necessário também, como destacado no corpo deste trabalho em Referências Técnicas para atuação de Psicólogos na Educação Básica

${ }^{7}$ Entrevistada B (entrevista concedida em 10 de outubro de 2018). 
(2013), que o profissional tenha acesso ao número de estudantes que fazem parte da escola, de professores, de turmas, de reuniões que foram realizadas e que estão sendo planejadas, de profissionais que atuam na rede e os dados relativos à localização da escola e da cidade que a mesma está inserida. Tais informações serão importantes para nortear a elaboração de planos de ação e de intervenções que poderão beneficiar a comunidade escolar e os profissionais que nela atuam.

Neste sentido, destacamos também que a/o psicóloga/o escolar tem como papel incentivar o movimento dos profissionais na escola, pois é necessário que toda a equipe esteja envolvida na busca de outros caminhos. Então, a profissional pode, neste espaço, promover indagações e encontrar brechas nos discursos, pois através deste meio é possível construir a movimentação de novos fazeres junto com as/os profissionais.

É de suma relevância também destacarmos a relação da psicologia e a inclusão. A entrevistada "A" afirmou que "A inclusão, pra mim, é a escola querer mudar e não querer que o aluno venha e se adeque. A inclusão é eu conseguir o meu espaço e acolher as diferenças do outro." A inclusão, portanto, sugere uma reelaboração do sistema educativo, já que ao invés de "adaptar" as crianças às instituições, tal prática busca alterar os olhares e visões cristalizadas presentes, propondo novos fazeres e considerando, sobretudo, a inclusão social através de um viés crítico e emancipador. A atuação no campo de psicologia escolar é fundamental para a promoção de reflexão sobre preconceitos que estão arraigados na escola, além de promover a construção de oportunidades para que as crianças com deficiência superem os limites colocados e se sintam pertencentes e autoras de transformações no contexto em que estão inseridas.

Cabe ressaltar que a entrevistada "B" também afirmou que a partir das intervenções, diálogos e projetos elaborados na escola, a mesma pode ter maior aproximação com as/os professoras/es, psicopedagoga e a profissional do atendimento educacional especializado (AEE). De acordo com esta psicóloga, essa proximidade com as/os outras/os profissionais da escola possibilitou maior interlocução também com crianças e pais, fortalecendo, portanto, os vínculos entre escola e comunidade.

Hoje eu posso dizer que eu saio daqui extremamente cansada, porque hoje, bom, quando você entra num lugar e você é novo né, o profissional é novo ali, ele tem que se descobrir, ele tem que entender [...], hoje, eu posso dizer que o meu trabalho tem sim, resultado, tem resultado por que eu percebo assim, muitos professores me procurando para tirar uma dúvida pra ir atrás, eu ando bastante na escola, tento ir atrás, dar sugestões, eu tento, eu entro em sala de aula, eu assisto aula, eu tento, sim, não é suficiente, [...] faço observações 
em sala, se precisar ajudar o professor a montar planejamento de aula, alguma coisa de acordo, eu ajudo (informação verbal) ${ }^{8}$.

Após as pontuações realizadas pelas profissionais entrevistadas, observamos que, apesar dos percalços vivenciados na prática, as mesmas construíram um espaço maior de diálogo com a equipe e os familiares. Evidencia-se que há muitos desafios na escola, porém a presença da/o Psicóloga/o Escolar é crucial na rede, pois esta/e pode trazer inquietações e apontamentos discursivos, além de construir novos fazeres junto a outros profissionais; auxiliar na elaboração e flexibilização do regimento escolar; promover a elaboração de projetos que auxiliarão a comunidade escolar; construir diálogo e aproximação na inter-relação entre família-escola.

Por fim, destacamos a importância de que na formação inicial as/os estudantes de psicologia possam vivenciar as rotinas escolares, tão marcadas por inconstâncias e desafios, porém repletas de vivências e singularidades. Salientamos também, a necessidade de incentivos através da formação continuada para oferecer suporte aos profissionais que já estão circunscritos no ambiente escolar. Torna-se perceptível a relevância da psicologia no campo educacional, para que estas/es profissionais possam contribuir na promoção de espaços mais democráticos e abertos às diferenças.

\section{Considerações finais}

Buscamos, por meio deste trabalho, divulgar os trabalhos das profissionais de Psicologia escolar do sul de Mato Grosso do Sul e expor suas dúvidas, contradições e desafios enfrentados. Acreditamos que as relações sempre serão perpassadas por desafios e que os mesmos fazem parte da atuação de profissionais que estão em um campo tão complexo como o da educação. Consideramos também que através da educação e da inclusão de todas as pessoas, alcançaremos uma sociedade mais democrática e diversa.

Frente às dificuldades encontradas para a efetivação de práticas inclusivas, cabe a reflexão acerca da formação de Psicólogas/os e também sobre a atuação destas/es nas instituições, ainda mais se considerarmos que a Psicologia teve em seu bojo a elaboração de práticas potencialmente elitistas e que, por vezes, auxiliaram na manutenção do status quo.

${ }^{8}$ Entrevistada B (entrevista concedida em 10 de outubro de 2018). 
Através das entrevistas realizadas, observamos que a atuação na área de Psicologia Escolar se mostra como um desafio para as profissionais, pois as mesmas encontram algumas dificuldades na execução de práticas inclusivas. Tais obstáculos concernem desde a dificuldade de compressão da comunidade escolar sobre a real atuação destas profissionais até a execução de planejamentos e projetos, considerando que constantemente a/o profissional de Psicologia é vista/o como aquela/aquele que terá resoluções mágicas para os problemas encontrados na instituição. As profissionais destacam a necessidade de formação continuada para professoras/es e de maiores diálogos com a comunidade escolar, já que a participação da família na escola ocorre de forma bem reduzida.

Salientamos a relevância de que a formação inicial de Psicólogas/os apresente em sua grade de disciplinas o estudo de políticas públicas e de legislações que norteiam os processos educativos. Ademais, o papel da/o profissional na escola é fundamental para promoção, junto com a comunidade escolar, de espaços inclusivos e democráticos que possibilitem a vivência da cidadania plena.

Outro apontamento necessário se refere à disseminação de laudos, da busca de respostas médico-assistencialistas pela comunidade escolar e, por vezes, das/os próprias/os Psicólogas/os Escolares para os desafios encontrados na escola. Porém, a função principal da Psicologia Escolar, conforme exposto no estudo, é fomentar o diálogo e a construção de novos saberes com os demais profissionais das instituições de ensino de maneira interdisciplinar.

Como exposto anteriormente, sabemos que há muitos trabalhos, tanto elaborados pelo Conselho Federal de Psicologia, como por profissionais em diferentes Universidades do Brasil, questionando este histórico e produzindo materiais que considerem a perspectiva inclusiva como fundamental para a diminuição de desigualdades sociais. Para isto, é preciso respeitar a singularidade do indivíduo e o seu modo de estar no mundo, bem como oferecer experiências de aprendizagens e mediações através da utilização de diversas técnicas e instrumentos potencializadores.

Verificamos também que a partir da intervenção que foi realizada através de projetos e diálogos com a comunidade escolar, as psicólogas puderam trazer a comunidade para a vida escolar. Isto confirma nossos apontamentos anteriores a respeito da relevância desta/e profissional dentro das escolas. Além disso, apesar dos desafios enfrentados no decorrer da trajetória profissional, as entrevistadas se mostraram atentas às legislações, atualizações na área e formações continuada. 
A partir do que foi destacado neste estudo, compreende-se que o aprofundamento teórico e o contato com o dia a dia escolar durante o curso de graduação em Psicologia é de suma relevância para as/os profissionais que atuam na escola. Quando o profissional atua na área da psicologia escolar com esta bagagem, as suas práticas podem ser mais éticas e humanizadas.

Por isso, é necessário que a/o profissional de educação tenha, como nos diz Asbahr (2014), um "olhar relacional" para as relações estabelecidas nas esferas institucionais. Ademais, cabe ressaltar que as Políticas Nacionais têm fomentado a inserção de programas inclusivos e que possam respeitar as diferenças de cada indivíduo. A inclusão, portanto, implica na mudança de visões cristalizadas, trazendo à tona a transformação das relações, promovendo assim a construção de uma sociedade mais justa, democrática e igualitária.

\section{REFERÊNCIAS}

ALMEIDA, Denise Mesquita de Melo. Ação docente e desenvolvimento local: o papel do Grupo das Meninas na construção das redes de sociabilidade e desenvolvimento de Amargosa/BA. Tese (Doutorado em Educação). Universidade Estadual de Campinas, Campinas, SP: 2014.

ALMEIDA, Denise Mesquita de Melo; GÉLLER, Léa. Psicologia e educação: transdisciplinaridade na construção do atendimento educacional especializado de Caarapó-MS. Revista on-line de Política e Gestão Educacional, [S.1.], p. 856-871, dec. 2018. ISSN 1519-9029. Disponível em:

https://periodicos.fclar.unesp.br/rpge/article/view/11917. Acesso em: 18 dez. 2018. DOI: https://doi.org/10.22633/rpge.unesp.v22.nesp2.dez.2018.11917.

ANTUNES, Mitsuko Aparecida Makino. Psicologia escolar e educacional: história, compromissos e perspectivas. Psicologia Escolar e Educacional, v. 12, n. 2, p. 469$475,2008$.

ASBAHR, Flávia da Silva Ferreira. Notas sobre o ensino de psicologia escolar em uma concepção crítica. Psicologia Ensino \& Formação, v. 5, n. 1, p. 20-31, 2014.

BRASIL. Lei no 8.069, de 13 de julho de 1990. Dispõe sobre o Estatuto da Criança e do Adolescente e dá outras providências. Disponível em:

http://www.planalto.gov.br/ccivil_03/leis/18069.htm. Acesso em: 15 maio 2019.

BRASIL. Lei no 9.394, de 20 de dezembro de 1996. Estabelece as diretrizes e bases da educação nacional. Disponível em:

http://www.planalto.gov.br/ccivil_03/leis/L9394.htm. Acesso em: 15 maio 2019. 
BRASÍLIA. Referências técnicas para Atuação de Psicólogas(os) na Educação Básica / Conselho Federal de Psicologia, CFP, 2013, 58p.

DIAS, Sueli de Souza; OLIVEIRA, Maria Cláudia Santos Lopes de. Inclusão como contexto de transição de desenvolvimento: Um olhar da Psicologia Escolar. In: FRANCISCHINI, Rosângela; VIANA, Meire Nunes. Psicologia Escolar: que fazer é esse? Brasília: CFP, 2016.

FLORES-MENDOZA, Carmem Elvira. Estudo exploratório sobre a atuação dos psicólogos escolares que trabalham com populações especiais em Mato Grosso do Sul. Estud. Psicol. (Campinas), Campinas, v. 14, n. 1, p. 71-82, 1997.

KASSAR, Mônica Carvalho Magalhães. Escola como espaço para a diversidade e o desenvolvimento humano. Educ. Soc., Campinas, v. 37, n. 137, p. 1223-1240, 2016.

MANTOAN, Maria Teresa Eglér. Inclusão escolar: O que é? Por quê? Como fazer? São. Paulo: Moderna, 2003.

OLIVEIRA-MENEGOTTO, Lisiane Machado de; FONTOURA, Gabriela Prado da. Escola e Psicologia: Uma História de Encontros e Desencontros. Psicol. Esc. Educ. Maringá, v. 19, n. 2, p. 377-386, 2015.

PATTO, Maria Helena Souza. Ciência e política na primeira república: origens da psicologia escolar. Mnemosine, 2004.

ROSA, Paulo Ricardo da Silva. Uma introdução à pesquisa qualitativa em ensino de ciências. Campo Grande: Universidade Federal de Mato Grosso do Sul, 2013.

SOUZA, Marilene Proença Rebello de. Psicologia Escolar e políticas públicas em Educação: desafios contemporâneos. Em Aberto, Brasília, v. 23, n. 83, p. 107-128, mar. 2010.

VIEGAS, Lygia de Sousa; HARAYAMA, Rui Massato; SOUZA, Marilene Proença Rebello de. Apontamentos críticos sobre estigma e medicalização à luz da psicologia e da antropologia. Ciênc. saúde coletiva, Rio de Janeiro, v. 20, n. 9, p. 2683-2692, 2015.

\section{Como referenciar este artigo}

ALTRÃO, Suéllen Soares; ALMEIDA, Denise Mesquita de Melo. Psicologia escolar e educação inclusiva: da formação às práticas de psicólogas escolares de Mato Grosso do Sul. Revista on line de Política e Gestão Educacional, Araraquara, v. 23, n. esp. 1, p. 728-742, $\quad$ out. $2019 . \quad$ E-ISSN:1519-9029. https://doi.org/10.22633/rpge.v23iesp.1.13018

\section{Submetido em: 10/05/2019}

Revisões requeridas: $14 / 06 / 2019$

Aprovado em: 10/08/2019

Publicado em: 01/10/2019 